\title{
Using evidence about clinical effectiveness in everyday psychiatric practice
}

\author{
John Geddes
}

\begin{abstract}
Most clinicians understand the advantages of basing their practice on the best avallable evidence, but sometimes doubls are voiced about the fecsibility of applying the strategies of evidence-based medicine (EBM) in everyday clinical practice. This article describes one strategy for beginning to use EBM in 'real-time' which could already be used by the majortly of clinicians. The rapld developments in clinical informatics are likely to enhance the feasibility and value of this strategy.
\end{abstract}

All healthcare professionals, including psychiatrists, are being urged to base their clinical decisions on the best available evidence. But how does a clinician find and use this evidence? With increasing demands from all sides, how does she find the time to track down and use evidence? It is easy to see the advantages of valid, explicitly 'evidence-based' and clinically useful guidelines as a means of providing pre-digested information for the clinician (Kendell, 1997), but these remain vanishingly rare, unlike the plethora of non-evidence-based clinical practice guidelines (which are always of uncertain validity; Hayward et al, 1995). Therefore, the clinician who is attempting to base her clinical decisions explicitly on evidence needs to develop her own strategies of searching for, appraising and using evidence. These will depend on her time, resources and creativity. However, there are already several feasible ways of using the strategies of evidence-based medicine (EBM) in 'real-time' clinical decision-making. This article demonstrates an example of how EBM can be used to answer a clinical question in real life psychiatry.

\section{Example}

Mrs A, a 45-year-old woman, arrives at Dr P's community mental health centre clinic with a note of an item she heard on Woman's Hour'. Dr $P$ has been treating Mrs A for a recurrent severe depressive disorder; she made a brief but unsustained improvement on fluoxetine $(40 \mathrm{mg}$ daily) and subsequently has made a partial but incomplete response to amitriptyline $(150 \mathrm{mg}$ daily). Mrs A complains bitterly of the side-effects she experienced with the fluoxetine. She also admits to some dry mouth and dizziness with the amitriptyline - although she is willing to tolerate this. She wonders if St John's wort might be just as effective an antidepressant and have fewer side-effects than conventional antidepressants. Mrs A is unwilling to try any other non-herbal antidepressants while St John's wort is an option. She asks Dr P for further information about St John's wort and wants to know whether she should obtain some from the local pharmacist. Dr P does not know what the evidence for effectiveness for St John's wort is, but he is keen to find out if there is any high-quality evidence (systematic review of randomised controlled trials) because he wants to advise lithium augmentation as the next treatment option. Dr $P$ therefore forms a structured four-part clinical question:

(1) In patients with moderate depressive illness (especially those, like Mrs A, who have failed to respond to initial antidepressant treatment),

(2) is St John's wort

(3) as effective as conventional antidepressant treatment

(4) in producing clinically significant improvement?

Dr $P$ telephones the librarian at the hospital and asks her to see if there are any systematic reviews of the efficacy of St John's wort in the Cochrane Library (Cochrane Collaboration. 1997). The Cochrane Library contains the Cochrane Database of Systematic Reviews (Fullerton-Smith, 1995), the Database of Abstracts of Reviews of Effectiveness (DARE; Sheldon, 1996) and the Cochrane Controlled Trials Register. DARE is a collection of quality-assessed structured abstracts and references of systematic reviews which is maintained by the UK National Health Service Centre for Reviews and Dissemination. While he waits, Dr $P$ confirms his 
diagnosis and asks the patient about possible maintaining factors. The librarian enters the key words - St John's wort - which allows her to search all databases in the Cochrane Library at the same time. She finds a structured abstract of the following paper on the DARE:

Linde, K., Ramirez, G., Mulrow, C. D., et al (1996) St John's Wort for depression - an overview and metaanalysis of randomised clinical trials. British Medical Journal, 313, 253-258.

The librarian immediately faxes the two-page abstract across to Dr P in the clinic. Dr P asks the patient to have a cup of tea while he critically appraises the abstract.

The DARE abstract summarises the objectives, design, methods and main findings of the review. It also gives a judgement of the overall quality of the review and an attempt at interpretation. Dr $P$ notes that the review included 1008 patients in 15 randomised controlled trials (RCTs) comparing variable preparations of hypericum against placebo, and 749 patients in eight RCTs comparing hypericum (in a wide range of preparations and doses) with a wide range of antidepressants (including maprotiline, bromazepam, amitriptyline, diazepam, desipramine and imipramine in unspecified doses). The search strategy used by the authors is given, and Dr P is confident that he could reproduce the search if required. The results from the original studies were performed in a range of settings and included a wide range of depressed patients, although they were mainly suffering from "mild to moderately severe depression".

Dr P concludes (as does the Centre for Reviews and Dissemination) that the review is of good quality. However, he is concerned that doses of neither the antidepressants (some of which are not normally considered to be antidepressants) nor the hypericum are adequately described. He also wonders how similar the participants in the trial are to Mrs A, who is quite severely depressed and has already failed to respond to two conventional antidepressants.

Dr $P$ then invites Mrs A back into his consulting room and explains to her that he does not think that there is sufficient evidence that St John's wort will help her for him to be able to recommend it. Dr P briefly explains his reasons (Mrs A does not want complicated explanations because her concentration is rather impaired). Dr $P$ then goes on to ask Mrs $A$ to consider lithium augmentation therapy. Now that $\mathrm{Dr} P$ has answered her question about St John's wort, Mrs A agrees to do so.

The whole consultation has taken $\mathbf{3 0}$ minutes, and so Dr P has some catching up to dol

The results section in the abstract caught Dr P's eye while he was assessing the review's validity and its applicability to his patient. The abstract states that hypericum extracts were significantly superior to placebo in effecting a response (pooled rate ratio, 2.67; 95\% CI 1.784.01), and as effective as standard antidepressants (odds ratio $1.10 ; 95 \% \mathrm{CI} 0.93-1.31$ ) and combinations (odds ratio $1.52 ; 95 \%$ CI $0.78-$ $2.94)$. There were two drop-outs $(0.8 \%)$ for sideeffects with hypericum and seven (3.0\%) with standard antidepressants. Side-effects were reported by $50(19.8 \%)$ patients taking hypericum and $84(35.9 \%)$ taking standard antidepressants. There is therefore $16.1 \%$ less chance of a patient taking hypericum reporting side-effects than a patient taking a conventional antidepressant. Put another way, Dr P would need to treat six patients with hypericum rather than a conventional drug to prevent one patient from reporting side-effects. Although $\mathrm{Dr} P$ is confident that he interpreted the evidence correctly for Mrs A, he decides that the results are sufficiently interesting for him to look at the original paper. There may be other groups of patients - for example. those seen by his general practitioner colleagues - for whom St John's wort might be useful. He decides to appraise the paper critically in the hour that he sets aside every week for continuing professional development. By keeping his own computerised record of his critical appraisal of the review, he will easily be able to refer to it again. He can keep his record up-to-date by using a current awareness journal such as Evidence-Based Medicine (the January/February 1997 issue includes a structured abstract and commentary of the St John's wort review) or the soon-to-be-launched Evidence-Based Mental Health.

\section{Starting to get evidence into practice}

This example illustrates the feasibility of using EBM in everyday clinical practice. Dr $P$ was perhaps fortunate to find the evidence he was looking for so easily, but clinicians are very busy and it is impractical to suggest that they should perform a computerised Medline search themselves every time they need information. Table 1 shows the trade-off between ease of use and availability of current sources of evidence. The situation is improving rapidly with the growth of the Cochrane Library and the initiation of programmes to develop evidence-based clinical practice guidelines (Marriott \& Palmer. 1996). The strategies used by Dr P are one way of starting to get evidence into practice and could be used at the present time by the majority of clinicians working in the NHS. This is accomplished by restricting initial searching to high quality and relatively trustworthy (although the user still needs to appraise them 
Table 1. Ease of access to evidence of effectiveness against current availability

\begin{tabular}{lll}
\hline & Ease of use & $\begin{array}{c}\text { Current } \\
\text { avallability }\end{array}$ \\
\hline $\begin{array}{l}\text { Evidence-based patient-specific reminders - appearing } \\
\text { on screen during consultation }\end{array}$ & +++++ & - \\
$\begin{array}{l}\text { Evidence-based clinical guidelines } \\
\text { Written abstract of systematic review (in DARE database } \\
\quad \text { or Evidence-Based Mental Health) }\end{array}$ & ++++ & $+/-$ \\
$\begin{array}{l}\text { Systematic reviews } \\
\text { Individual studies }\end{array}$ & +++ & ++ \\
\hline
\end{tabular}

Table 2. How to evaluate a systematic ovenview (modified from Sackett et al, 1997)

1. Is it an overview of randomised trials of the treatment that you're interested in?

YES $\square \quad$ NO $\square$

2. Does it include a methods section that describes:

a. How the individual trials were found and included?

b. How the validity of the individual trials was assessed?

1. Was the assignment of patients to treatments truly randomised?

2. Were the groups similar at the start of the trial?

3. Were patients and clinicians kept blind to which treatment was being received?

4. Aside from the experimental treatment, were the groups treated equally?

5. Were all the patients who entered the trial accounted for at its conclusion?

3. Were the results of the studies consistent from study to study?

$\begin{array}{ll}\text { YES } & \text { NO } \\ \text { YES } & \text { NO } \\ \text { YES } & \text { NO } \\ \text { YES } & \text { NO } \\ \text { YES } & \text { NO } \\ \text { YES } & \text { NO } \\ \text { YES } & \text { NO } \\ \text { YES } & \text { NO } \\ & \\ \text { RRR } & \\ \text { ARR } & (95 \% \mathrm{Cl}) \\ \text { NNT } & (95 \% \mathrm{Cl})\end{array}$

4. What are the results?

a. Relative risk reduction

b. Absolute risk reduction

c. Number needed to treat

NNT $=$

5. Do these results apply to your patient?

a. Is your patient so different from those in the overview that its results can't help you?

b. How great would the potential benefit of therapy actually be for your individual patient?

c. Are your patient's values and preferences satisfied by the regimen and its consequences?

critically - caveat emptorl) sources of structured abstracts of systematic reviews such as those published in the Cochrane Library. Systematic reviews or overviews of RCTs are recognised as being the most reliable form of evidence about a therapeutic intervention. All NHS libraries should have subscriptions to the Cochrane Library, and librarians are actively developing their roles as information providers. Trusts vary in how successfully they have implemented computer networks and how easy it is for (often geographically isolated) clinicians to access information; the use of the relatively 'primitive' technology of the fax machine allows rapid transmission of printed information. An initial meeting would be required between the clinician and the librarian to agree on sources of evidence to be searched and the hierarchies of research design to apply.
The example also illustrates that Dr P needed to use his clinical expertise to assess the applicability of the evidence from the systematic review for Mrs A (see Table 2). Evidence-based practice does not lead to certainty because evidence rarely precisely 'fits' an individual patient. Other factors such as clinical judgment and patient preferences are important in making clinical decisions.

\section{References}

COCHRANE Collaboration (1997) The Cochrane Library. Issue 1. Oxford: Update Software.

FULLERTON-SMTT, I. (1995) How members of the Cochrane Collaboration prepare and maintain systematic reviews of the effects of health care. Evidence-Based Medicine. 1, 7-8. 
HAYWARD, R. S., Wilson, M. C.. TUNIS, S. R., et al (1995) Users' guides to the medical literature. VIII. How to use clinical practice guidelines. A. Are the recommendations valid? The Evidence-Based Medicine Working Group. Joumal of the American Medical Association, 274, 570-574.

KENDEL, R. E. (1997) The College and 'clinical effectiveness' Psychiatric Bulletin, 21, 385-386.

MARRIOTT, S. \& PALMER, C. (1996) Clinical practice guidelines: on what is our clinical practice based? Psychiatric Bulletin, 20, 363-366.
SACKETT, D. L., RICHARDSON. S.. ROSENBERG, W.. et al (1997) Evidence-Based Medicine: How to Practice and Teach $E B M$. London: Churchill-Luvingstone.

SHELDON, T. A. (1996) Research intelligence for policy and practice: the role of the National Health Service Centre for Reviews and Dissemination. Evidence-Based Medicine, 1, 167-168.

John Geddes, Senior Clinical Research Fellow, University Department of Psychiatry. Warneford Hospital, Oxford OX3 7JX 